\title{
GERÇEK-ZAMANLI, KISA MESAFELI VE YAZILIM TABANLI BİR SAYISAL KABLOSUZ HABERLEŞME ALICI-VERİCI TASARIMININ GERÇEKLEMESİ
}

\author{
Merve AKIN ${ }^{1}$, Meryem ÇAKIR ${ }^{1}$, Dilara YILDIZ ${ }^{1}$, Haluk ÖZGEN ${ }^{1}$, Serhan YARKAN ${ }^{2}$

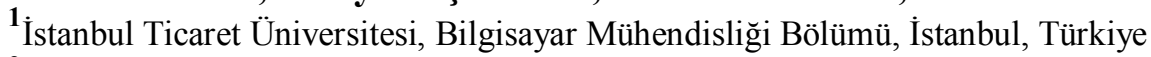 \\ 2 İstanbul Ticaret Üniversitesi, Elektrik-Elektronik Mühendisliği Bölümü, İstanbul, Türkiye \\ 1105.02015@istanbulticaret.edu.tr, meryemcakir@istanbulticaret.edu.tr, \\ 1105.02029@istanbulticaret.edu.tr, $1105.02033 @$ istanbulticaret.edu.tr, syarkan@ticaret.edu.tr
}

(Geliş/Received: 23.05.2014; Kabul/Accepted: 16.10.2014)

ÖZET

Kablosuz haberleşme sistemlerinde alıcı-verici tasarımlarının fiziksel katmanı, sistemin bütününün inşasında oldukça önemli bir yer tutmaktadır. Ancak her yeni çıkan kablosuz haberleşme teknolojisi, hem alıcı-verici tasarımlarının hem de bu tasarıma ait donanımın yenilenmesini zorunlu kılmaktadır. Bunun yanında, sayıları hızla artan kablosuz haberleşme sistemleri, sınırlı ve oldukça değerli bir kaynak sayılan radyo spektrumunun da verimli kullanılması konusunu gündeme getirmektedir. Yakın zamanda ortaya atılan akıllı radyo kavramı; yazılım-tabanlı platform üzerinde çalışmasııın bir sonucu olarak; esnek tasarım, değişen koşullara hızlı ve etkin bir biçimde uyum sağlama, spektrumun kullanım durumundan haberdar olma ve öğrenme gibi özellikleri ile sözü edilen konulara yeni bir bakış açısı getirmektedir. Bu çalışmada, akıllı radyo hedefine ulaşma amacı doğrultusunda temel bantta çalışan ve bütün değişkenleri geliştirici tarafindan ayarlanıp, denetlenip, güncellenebilen yazılım-tabanlı bir kablosuz akustik alıcı-verici tasarımı ortaya konmuştur. Tasarım ile ilgili kuramsal ve simülasyon tabanlı çözümlemeler verilmiştir. Tasarımın gerçek-zamanlı olarak çalışan bir öntürü gerçeklenmiştir. Aynı öntür yazılım-tabanlı platformlar için de birçok karşılaştırmanın yapılabileceği bir sınama ortamı olarak kullanılabilmektedir. Başarım sonuçları, ilgili tartışmalar ve geleceğe yönelik çalışmalarla birlikte irdelenmiştir.

Anahtar Kelimeler: Akustik, kablosuz haberleşme, kısa mesafe, temel bant, yazılım tabanlı haberleşme, akıllı radyo, bilişsel radyo, simülasyon, sinama ortamı

\section{A LOW-COST, REAL-TIME, AND SHORT-RANGE SOFTWARE-DEFINED DIGITAL WIRELESS COMMUNICATIONS TRANSCEIVER DESIGN AND IMPLEMENTATION AT BASEBAND}

\begin{abstract}
Physical layer transceiver design lies in the heart of all wireless communications systems. However, each and every emerging wireless communications technology forces the already-existing transceiver designs and their corresponding hardware to change. In addition, due to the dramatic increase in number of emerging wireless technologies, there are serious concerns regarding the utilization of valuable radio spectrum. Recently, cognitive radio concept is proposed in order to provide a new perspective for the aforementioned concerns. Operating on a software-defined platform, cognitive radio introduces flexibility in design of utmost level; adapts itself to the dynamic radio environment; senses the radio spectrum steadily to be aware of it; and learns about its past experiences in order to plan and take action in the future in a beter way. Therefore, in this study, a softwaredefined wireless acoustic baseband transceiver design whose each and every parameter could be modified, updated, and changed with utmost flexibility is established toward realization of cognitive radio. Mathematical analysis and a simulation environment of the design are provided too. A real-time implementation of the transceiver is realized as well in order to both demonstrate an operating prototype and set up a testbed for
\end{abstract}


software-defined platforms. Results for theoretical, simulation, and real-time performance of the transceiver are given along with relevant discussions and future directions.

Keywords: Acoustic, baseband, short-range, software-defined radio, wireless communications, cognitive radio, simulation, testbed

\section{GİRIŞ (INTRODUCTION)}

Bilimsel dizinde iletim ortamları fiziksel özelliklerine göre kablolu, kablosuz ve her ikisini aynı anda bir arada içeren karma (hibrit) ortamlar olarak sınıflandııılır. Ancak haberleşme altyapısının kablolu, kablosuz ya da karma olması alıcı-verici tasarımı açısından bakıldığında aslında çok da büyük önem taşımamaktadır. Alıcı-verici tasarımı için en önemli öge, haberleşme kanalının davranışının matematiksel modelidir. Haberleşme kanalı, gürültü, girişim ve hareketlilik gibi etkenlerden ötürü çoğu zaman rastlantısal davranışlar sergilemektedir. Rastlantısal davranış açısından bakıldığında, kablolu haberleşme kanalı istatistiki anlamda durağan ya da çok az değişkenlik gösteren bir sınıfa karşıllık gelmektedir. Buna karşın kablosuz haberleşme kanal, istatistiki anlamda oldukça fazla değişkenlik gösteren bir sınıfı temsil eder. Kanalların davranış istatistiklerinde görülen bu farklılıklar nedeniyle, genelde kablosuz haberleşme sistemlerindeki alıcı-verici tasarımları daha karmaşık; dolayısıyla daha maliyetlidir. Bu karmaşıklığa karşın bakım ve sürdürülebilirlik maliyetleri ile birlikte hareketlilik desteği düşünüldüğünde, kablosuz haberleşme sistemleri sıkça tercih edilmektedir. Buna ek olarak, yeni çıkan teknolojilerin uzun bir süre eskileriyle bir arada çalışmak zorunda olması ve donanım değişikliği zorunluluğu, hâlihazırdaki kablosuz teknoloji kalabalığının daha da artacağına ilişkin haklı beklenti ve radyo spektrumunun verimsiz kullanımı [1,2] gibi birçok husus ve kaygı, alıcı-verici tasarımında köklü bir değişikliğe gidilmesini öngörmektedir. Son dönemde akıllı radyo olarak ileri sürülen kavram [3], kendisini değişen haberleşme koşullarına göre hızlıca ve en etkin biçimde ayarlayabilen, haberleşme katmanları arasında veriyi oldukça etkin bir biçimde dolaştırabilen ve önceki durumlardan hareketle öğrenebilen bir teknolojiyi gündeme getirmektedir [4]. Ak1ll radyonun burada listelenen hedeflerin tümüne ulaşmasının yolu "yazılım-tanımlı radyo" olarak da bilinen bir yazılım-tabanlı platformdan (YTP) geçmektedir [3]. Dolayısıyla akıllı radyonun gerçek olabilmesi için üzerinde duracağı YTP'nin gerçeklenmesi kaçınılmazdır.

Bilimsel dizinde birçok yazılım-tabanlı radyo gerçeklemesi bulunmaktadır. $\mathrm{Bu}$ çalışmalar birkaç farklı şekilde sınıflandırılabilir. Sinıflandırma stratejisi olarak Open System Interconnection (OSI)'nin yedi katmanlı modeli kullanıldığında, bilimsel dizinde mevcut çalışmaların henüz alt katmanlarda ilerlediği, üst katmanlarda ise henüz fazla bir ilerlemenin olmadığı görülmektedir.
Gerçeklemelerde de doğrudan donanıma hükmedebilen platformlardan daha çok hazır olanlar tercih edilmektedir. Örneğin; [5]'te akıllı radyoların kaynakları verimli biçimde yönetebilmesi için OSI Katman-I ve II'deki belli başlı özelliklere yönelik bir benzetim kullanılmıştır. Aynı amaca yönelik olarak öne çıkan bir diğer hazır platform da USRP-GNU'dur $[6,7]$. Benzer şekilde [8]'de, WARP adı verilen bir başka hazır platforma dayanarak gerçek-zamanlı çalışma desteği ile birlikte bir akıllı radyo tasarımı ortaya konmuştur. Sözü edilen platformlar ile benzeri diğer platformların bulunduğu ve bunlar üzerinde ortaya konan gerçeklemelere ilişkin çalışmaların bir arada listelendiği bir çalışma olarak [9] incelenebilir. Ayrıca yazılım-tabanlı alıcı-verici tasarımının genel bir sayısal işaret işleme ya da benzeri özelleşmiş bir cihaz (FPGA gibi [10]) yerine çeşitli donanım bileşenleri üzerinde gerçeklenmesine yönelik olarak da önemli çalışmalar bulunmaktadır [11]. Donanım tarafinda sayılabilecek çalışmaların bir kısmı ise akıllı radyolar için oldukça önemli olan radyo ön ucuna yoğunlaşmıştır [12].

Bilimsel dizinde düşük ya da yüksek seviyeli birçok hazır YTP bulunmaktadır. Fakat yazılım-tabanlı bir alıcı-verici tasarımı gerçekleştirmek üzere hazır YTP'ler kullanılması, tasarım esnekliğinin ve derinliğinin bütünüyle geliştiricinin denetiminde olmasını engellemektedir. $\mathrm{Bu}$ sebepledir ki; bu çalışmada, temel bantta çalışan ve bütün değişkenleri geliştirici tarafindan ayarlanıp, denetlenip, güncellenebilen yazılım-tabanlı bir kablosuz akustik alıcı-verici tasarımı ortaya konmuştur. Tasarım ile ilgili kuramsal ve benzeşim tabanlı çözümlemeler verilmiştir. Tasarımın gerçek-zamanlı olarak çalışan bir öntürü gerçeklenmiştir. Başarım sonuçları, ilgili tartışmalar ve geleceğe yönelik çalışmalarla birlikte irdelenmiştir.

\section{YÖNTEM (METHOD)}

Tasarlanan haberleşme sistemi; bir alıcı, bir verici ve bu alıcı-verici çiftinin, üzerinden haberleşebileceği bir kanaldan oluşmaktadır. Buna ek olarak, verici tarafta hazır bulunan bir sayısal ileti olduğu da düşünülmektedir. Verici, hazır bulunan bu iletiyi uygun biçime dönüştürerek haberleşme kanalı aracılığıyla alıcı tarafa göndermektedir. Bu çerçevede amaç; haberleşme kanalından geçip, alıcıya ulaşan işarete bakılarak verici tarafindan gönderilen asıl iletinin alıcı tarafta yeniden oluşturulabilmesini sağlamaktır. İlgili amacın yanında, ayrıca alıcı tarafta kestirimlerin hatalı olması durumu incelenerek, sistem başarımının ölçülmesi de hedeflenmektedir. 


\subsection{Sistem ve İşaret Modeli (System \& Signal Model)}

Kablosuz haberleşme sistemleri, birçok nedenden (çoklu erişim, anten boyutu vb.) ötürü geçirme bandında çalışmaktadır. Ancak geçirme bandı ve temel bant matematiksel çözümleme açısından birbirine denktir [13,14]. Dolayısıyla bu çalışmada daha kolay izlenebilen bir çözümleme için temel bant yaklaşımı tercih edilmektedir. Ek olarak, çalışmanın tamamında ayrık zamanlı bir sayısal haberleşme sistemi göz önünde bulundurulmaktadır. $\mathrm{Bu}$ bağlamda, alınan işaret temel bantta:

$$
r[k]=d[k]+n[k]
$$

ile verilir. Haberleşme kanalı modellemelerinde kullanılan toplamsal gürültü çeşitleri arasında en çok beyaz Gauss gürültüsü kullanılır [15]. Bu çalışmada sayfa sınırlaması nedeniyle, yapılan çözümlemelerin daha kısa olması için $[a, b]$ aralığında tekdüze dağılıma sahip, örneklerinin birbirinden bağımsız olduğu varsayılan bir gürültü modeli, $n[\cdot]: U D(a, b)$ seçilmiştir. Ancak bilinmelidir ki, çözümlemede kullanılan yöntemler ve akıl yürütmeler her türden toplamsal gürültü için geçerlidir. Yukarıda (1) ile verilen $d[\cdot]$ için sonlu bir abeceden $d[k] \mathrm{B}\left\{A_{0}, A_{1}, \ldots, A_{M-1}\right\} \quad$ ve $\quad \forall k, d[k] \in \mathbf{R}$ olacak şekilde seçim yapıldığı varsayılmaktadır. Herhangi bir $A_{m}$ simgesinin $(m=0,1, \ldots, M-1)$ verici tarafta gönderilmek üzere seçilme olasılığı $p_{m}$ ile gösterilirse, $\forall p_{m} \in[0,1]$ olmak üzere $\sum_{m=0}^{M-1} p_{m}=1$ koşulunun sağlandığ bilinmektedir. $\mathrm{Bu}$ çalışma özelinde, çözümlemede $M=2$ ve $p_{0}=p \quad$ iken $\quad p_{1}=1-p \quad$ varsayılmaktadır. Dolayısıyla $M=2$ uyarınca herhangi bir $k$ dizinli anda gönderilmek istenen bit $b_{v}[k]$ ile temsil edilmek üzere, $s \in\{0,1\}$ olacak biçimde $\left\{b_{v}[k]=(s)_{2}\right\} \mapsto\left\{d[k]=A_{s}\right\} \quad$ bit-simge eşleşmesinin gerçekleştirildiği ve $d[k]$ simgesinin gönderildiği düşünülmektedir. Son olarak, alınan işaret $r[\cdot]$ 'yi oluşturan $d[\cdot]$ ve $n[\cdot]$ rastgele süreçlerinin istatistiki anlamda birbirinden bağımsız olduğunun kabul edildiği belirtilmelidir. Tüm bu varsayımlar ışığında alınan işaret $r[k]$ 'nın olasılık yoğunluk fonksiyonu (OYF): $f_{r}(x)=\left\{\begin{array}{ccc}\frac{p}{b-a} & , & a+A_{0} \leq x \leq b+A_{0} \\ \frac{1-p}{b-a} & , & a+A_{1} \leq x \leq b+A_{1} \\ 0 & , & \text { diğer }\end{array}\right.$

biçiminde parçalı olarak ifade edilir. Alıcının $r[k]$ 'yı esas alarak bir kestirimde bulunması, yani $k$ dizinli anda gönderilen simgenin $A_{0} \mathrm{~m}$, yoksa $A_{1}$ mi (ya da alınan bitin, sirasıyla, $b_{a}[k]=(0)_{2} \mathrm{~m}$, yoksa $b_{a}[k]=(1)_{2} \quad$ mi) olduğunu kestirmesi beklenmektedir. $\mathrm{Bu}$ amaçla alıcı, $c[k]$ kestirimini önceden belirlenmiş bir th eşik değeri aracılığı ile:

$c[k]=\left\{\begin{array}{ll}\hat{A}_{0}, & r[k] \leq t h \\ \hat{A}_{1}, & r[k]>t h\end{array}\right.$.

olacak biçimde elde eder. Son olarak $c[k]$ kestirimi, yukarıda değinilen bit-simge eşleşmesi uyarınca $\left\{c[k]=\hat{A}_{s}\right\} \mapsto\left\{b_{a}[k]=(s)_{2}\right\}$ dönüşümüne tabi tutulur.

\subsection{Alınan İşaretin Çözümlemesi (Analysis of The Received Signal)}

Yukarıdaki bilgiler 1şığında, alıcının kestirimi için dört farklı durum söz konusu olabilir. $\mathrm{Bu}$ durumlar $d[k] \mathrm{B}\left\{A_{0}, A_{1}\right\}$ ve $c[k] \mathrm{B}\left\{\hat{A}_{0}, \hat{A}_{1}\right\}$ iken:

$$
\begin{aligned}
d[k] \times c[k] & = \\
& \{\underbrace{\left(A_{0}, \hat{A}_{0}\right),\left(A_{1}, \hat{A}_{1}\right)}_{c_{D}[k]}, \underbrace{\left(A_{0}, \hat{A}_{1}\right),\left(A_{1}, \hat{A}_{0}\right)}_{c_{H}[k]}\}_{k}
\end{aligned}
$$

Kartezyen çarpımı ile ifade edilir. Gösterimde sadeliği sağlamak için bu noktadan sonra $k$ dizini kullanılmayacaktır. Aksi belirtilmedikçe bütün hesaplamaların herhangi bir $k$ dizinli anda gerçekleştiği varsayılacaktır.

\subsection{Hatasız Kestirim Durumunun Çözümlemesi (Error-free-Case Analysis)}

Alıcının kestiriminin hatalı ya da hatasız olması seçilen th eşik değerine bağlıdır. Hatasız kestirim $\operatorname{Pr}\left(c_{H}\right)=0$ olasılık ölçüsüne denktir. Örneğin; $c_{H}=\left(A_{0}, \hat{A}_{1}\right)$ için: 


$$
\operatorname{Pr}\left(\left(A_{0}, \hat{A}_{1}\right)\right)=\operatorname{Pr}\left(\left\{d=A_{0}\right\} \wedge\left\{c=\hat{A}_{1}\right\}\right)
$$

geçerlidir. Bu bağlamda $\hat{A}_{1}$ kestiriminin elde edilmesi için eşik değerinin $b+A_{0}<t h<a+A_{1}$ koşulunu sağlayacak biçimde seçildiği varsayılsın. Hesaplamalarda sadelik açısından bir an için $b+A_{0} \leq a+A_{1}$ olduğu da kabul edilsin. Yukarıda $\left\{d=A_{0}\right\}$ ile betimlenen olay, aynı zamanda alınan işaret cinsinden ifade edildiğinde (gürültünün istatistiği de göz önünde bulundurularak) $r=A_{0}+n$ olur. Dolayisıyla $\quad\left\{d=A_{0}\right\} \quad$ yerine $a+A_{0} \leq r \leq b+A_{0}$ yazılabilir. Aynı akıl yürütme ile $\left\{c=\hat{A}_{1}\right\}$ yerine de $t h \leq r$ yazilabilir. Ancak başta $\quad b+A_{0}<t h<a+A_{1} \quad$ varsayıldığından $\left\{c=\hat{A}_{1}\right\} \quad$ aynı $\quad$ zamanda $\quad b+A_{0}<r<b+A_{1}$ demektir. $\mathrm{Bu}$ durumda hem $\left\{d=A_{0}\right\}$ hem de $\left\{c=\hat{A}_{1}\right\}$ olaylarının aynı anda gerçekleşmesi, $a+A_{0} \leq r \leq b+A_{0}$ ile $b+A_{0}<r<b+A_{1}$ 'nin kesişimi demek olduğundan $\left\{d=A_{0}\right\} \cap\left\{c=\hat{A}_{1}\right\}=\varnothing$ elde edilir. Kolmogorov belitleri uyarınca $A_{0}$ ve $\hat{A}_{1}$ olaylarının bir arada gerçekleşmesine ilişkin olasılık ölçüsü, $r$ rastgele değişkeninin kümelerle ifade edilmesi ile birlikte düşünüldüğünde:

$$
\begin{aligned}
\operatorname{Pr}\left(\left(A_{0}, \hat{A}_{1}\right)\right) & \equiv \operatorname{Pr}\left(\left\{d=A_{0}\right\} \wedge\left\{c=\hat{A}_{1}\right\}\right) \\
& =\operatorname{Pr}\left(\begin{array}{l}
\left\{r \mid a+A_{0} \leq r \leq b+A_{0}\right\} \\
\bigcap\left\{r \mid b+A_{0}<r<b+A_{1}\right\}
\end{array}\right) \\
& =\operatorname{Pr}(\varnothing)=0
\end{aligned}
$$

sonucunu verecektir. Aynı akıl yürütmenin ve işlemlerin $b+A_{0}<t h<a+A_{1}$ varsayımı 1şığında $\left(A_{1}, \hat{A}_{0}\right)$ için de geçerli olması nedeniyle $\operatorname{Pr}\left(\left(A_{1}, \hat{A}_{0}\right)\right)=0$ elde edilecektir.

\subsection{Hatalı Kestirim Durumunun Çözümlemesi (Erroneous-Case Analysis)}

Alıcinın hatalı kestirimlerde bulunması $b+A_{0}<t h<a+A_{1}$ varsayımının ihlal edilmesiyle ortaya çıkar. Olasılık ölçüsü çerçevesinde ise bu durum $0<\operatorname{Pr}\left(c_{H}\right)$ ile ifade edilir. Buradan da hareketle, Kolmogorov belitleri doğrultusunda $\left\{d=A_{s}\right\} \cap\left\{c=\hat{A}_{1-s}\right\} \neq \varnothing \quad$ olacağı açıktır. Çözümlemenin en genel hali göz önünde bulundurularak $s=0$ durumu incelenebilir. $\mathrm{Bu}$ koşullar altında alıcının eşik değerini $a+A_{0}<t h<b+A_{0} \quad$ olacak şekilde seçtiği varsayılırsa, hem $\left\{d=A_{0}\right\}$ hem de $\left\{c=\hat{A}_{1}\right\}$ olaylarının aynı anda gerçekleşmesi, $r$ için $a+A_{0} \leq r \leq b+A_{0} \quad$ ile $t h<r \leq b+A_{0} \quad$ 'nin kesişimi anlamına gelmektedir. Açıtır ki, $\left\{d=A_{0}\right\} \cap\left\{c=\hat{A}_{1}\right\} \quad$ ile $\quad t h<r \leq b+A_{0}$ birbirlerine denktir. Buradan da:

$$
\begin{aligned}
\operatorname{Pr}\left(\left(A_{0}, \hat{A}_{1}\right)\right) & \equiv \operatorname{Pr}\left(\left\{t h<r \leq b+A_{0}\right\}\right) \\
& =\int_{t h}^{b+A_{0}} f_{r}(x) d x \\
& =\frac{p}{b-a}\left(b+A_{0}-t h\right)
\end{aligned}
$$

elde edilir. Aynı akıl yürütme $s=1$ durumu için alıcının eşik değeri th 'yi $a+A_{1}<t h<b+A_{1}$ olacak şekilde seçtiği varsayımıyla gerçekleştirildiğinde:

$$
\operatorname{Pr}\left(\left(A_{1}, \hat{A}_{0}\right)\right)=\frac{1-p}{b-a}\left(t h-\left(a+A_{1}\right)\right)
$$

sonucunu verir. Hatırlanacak olursa, (7) ve (8) ile belirtilen durumlarda $b+A_{0} \leq a+A_{1}$ varsayımı ile hareket edilmektedir. $\mathrm{Bu}$ varsayım, alıcının herhangi bir anda yalnızca tek türde hata yapacağı anlamına gelmektedir. Ancak gürültünün istatistiği $n[\cdot]: U D(a, b) \quad$ ile $\quad d \mathrm{~B}\left\{A_{0}, A_{1}, \ldots, A_{M-1}\right\}$ simgelerinin keyfi seçimi birlikte $a+A_{1}<b+A_{0}$ durumunu ortaya çıkarabilir. $\mathrm{Bu}$ durumda alıcı herhangi bir anda her iki hata türünden $\left(b_{v}=(0)_{2}\right.$ iken $b_{a}=(1)_{2}$ olarak kestirilmesi ya da tam tersi) birini yapacaktır. Böylesi bir senaryoda (7) ve (8) ile belirtilen hata oranları aynı şekilde hesaplanmasına karşın alıcının toplam hata oranı:

$$
\begin{aligned}
\operatorname{Pr}\left(c_{H}\right) & =\operatorname{Pr}\left(\left(A_{0}, \hat{A}_{1}\right) \vee\left(A_{1}, \hat{A}_{0}\right)\right) \\
& =\frac{1}{b-a}\left[\begin{array}{l}
p\left(b+A_{0}-t h\right) \\
+(1-p)\left(t h-\left(a+A_{1}\right)\right)
\end{array}\right]
\end{aligned}
$$


olacaktır.

Buraya kadar gerçekleştirilen tüm çözümlemeler, bilimsel dizinde sıkça kullanılan toplamsal beyaz Gauss gürültüsü seçilmesi durumunda da geçerlidir. Gürültü istatistiğinin $n[\cdot]: N(0,1)$ olacak şekilde seçilmesi durumunda, (7)'de kolayca hesaplanılan tümlevin kapalı biçimdeki ifadesi bulunamaz. Bu nedenden ötürü, toplam hata oranı; hata fonksiyonu gibi yardımcı fonksiyonlar üzerinden oluşturulmuş tablolar ya da sayısal yöntemler kullanan bilgisayarlar aracılığg ile hesaplanır [15].

\section{BULGULAR (RESULTS)}

Alıcı-verici tasarımlarında sıkça kullanılan bit-hata oranı, başarımın ölçülebilmesi ve karşılaştırılabilmesi anlamında en öne çıkan ölçüttür. Hatırlanacak olursa, (6) alıcının kestirimlerinin hatasız olması durumunu temsil etmektedir. Ancak bu durum başarımın ölçülmesi ya da karşılaştırılması anlamında herhangi bir bilgi vermez. Gürültünün istatistiğinin $n[\cdot]: \quad U D(a, b)$ olarak değil de $n[\cdot]: N(0,1)$ olması durumunda kestirimlerin hatasız olarak elde edilemeyeceği açıktır. Bu nedenlerden ötürü önce (7) ve (8) durumları ele alınacak, sonra da $n[\cdot]: \quad N(0,1)$ durumu irdelenecektir.

Gerçekleme adımına geçmeden önce bit-hata oranının kuramsal olarak öngörülen değerlerinin simülasyon ortamında da elde edilip edilemeyeceğine bakmak yerinde olacaktır. Bu amaçla akış çizelgesi Şekil 1'de verilen bir bilgisayar simülasyonu, Python 2.7.3 programlama dili kullanılarak yazılmıştır. Verici tarafta hazır bulunan ileti, bir dosyada tutulan ve karakterlerden oluşan rastgele bir metindir. Karakterlerin bitlere dönüştürülmesi için ASCII biçimi kullanılmıştır.

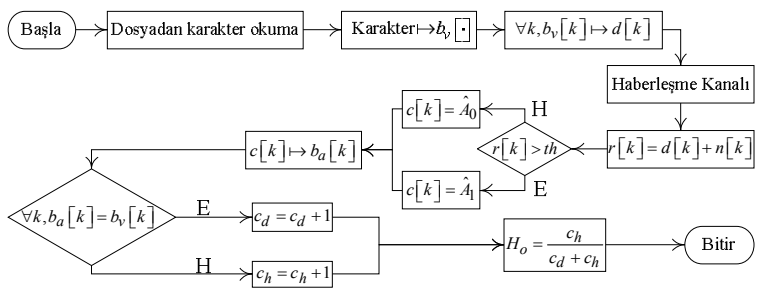

Şekil 1. Çözümlemede kullanılan sistem ve işaret modeline ilişkin simülasyonun akış çizelgesi (Flowchart of the simulation based on the system and signal model adopted)

Hem kuramsal inceleme hem de simülasyon çıktıları Şekil 2'de verilmiştir. Burada, $n[\cdot]: U D(0,1)$; $p=0.727 ; A_{0}=-A_{1}=-1$ olarak seçilmiştir.

Şekil 2'de de görüldüğü üzere kuramsal sonuçlar ile simülasyon sonuçları tam olarak örtüşmektedir. Beklendiği biçimde eşik değerinin konumu sıfira yaklaştıkça, hata oranı giderek azalmaktadır. Bu noktada belirtilmesi gereken en önemli hususlardan biri de; yukarıdaki eğrinin çeşitli "işaretin-gücününgürültünün-gücüne oranı (İGO)" değerleri için özdeş davranışlar sergileyeceğinin bilinmesidir. Dikkat edilirse $n[\cdot]: U D(0,1)$ ile birlikte $A_{0}=-A_{1}=-1$ durumları, İGO değerinin $10 \log _{10}\left(P_{d} / P_{n}\right) \cong 4.77 \mathrm{~dB}$ olmasını gerektirir.

Her ne kadar $P_{n}$ 'in sabit tutulup, $P_{d}$ 'nin arttırılması (örneğin; $A_{0}=-A_{1}=-2$ yapılması) İGO'nun artmasına neden olsa da $b+A_{0} \leq a+A_{1}$ koşulu sağlandığı sürece alıcının başarımında hiçbir değişiklik olmaz. Bu nedenle, $n[\cdot]: U D(0,1)$ için en uygun alıcı, İGO'nun yaklaşık $4.77 \mathrm{~dB}$ değerine ulaşması ile elde edilir. Ancak böyle bir yorum $n[\cdot]: \quad N(0,1)$ seçilmesi halinde yapılamaz.

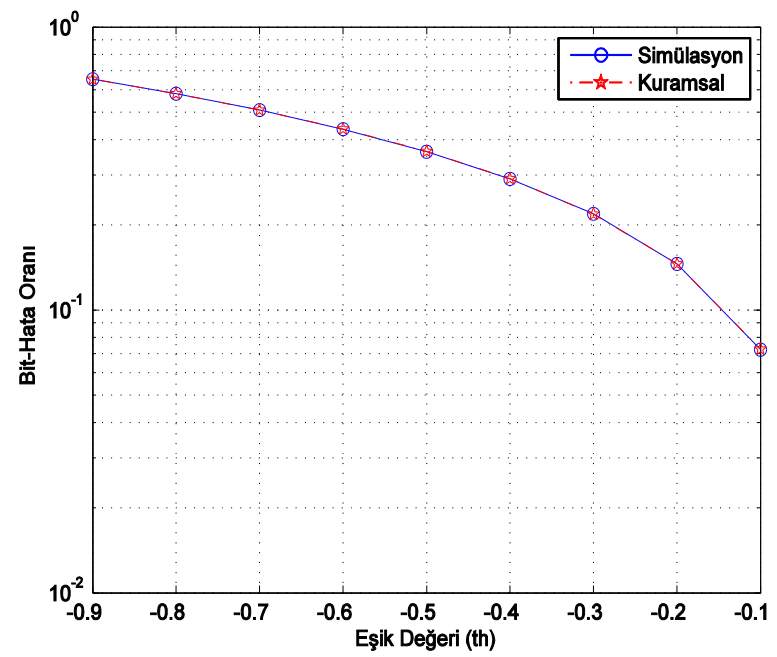

Şekil 2. Tekdüze dağılımlı toplamsal gürültü kanalına ilişkin kuramsal ve simülasyon sonuç eğrileri (Both theoretical and simulation results for uniformly distributed additive noise channel)

$\mathrm{Bu}$ çalışmada gerçekleme; yazılım-tabanlı radyo olarak akustik haberleşme yapan bir alıcı-verici şeklinde ortaya konmuştur. Hem alıcı hem de verici donanımı, gerçeklemenin oldukça hızlı ve düşük maliyetli olabilmesi adına standart ses kartına sahip dizüstü bilgisayarlardan seçilmiştir. Bu bilgisayarlar yazılım-tabanlı radyo kavramı uyarınca haberleşmede kullanılan değişkenlerin (simge oranı, taşıyıcı frekans değeri vb.) gerçek-zamanlı olarak MATLAB üzerinden değiştirilebilmesine (ve çalıştırılmasına) olanak sağlar özelliktedir. Alıcı - vericiye ilişkin gerçeklemenin kurulum örneği Şekil 3 'te verilmiştir.

Verici; simgelere dönüştürülüp uygun biçime sokulmuş iletiyi, hoparlörü aracılı̆̆ ile ses (akustik enerji) olarak ortama aktarır. Alıcı; sesi ilgili dizüstü bilgisayarın ses kartı girişine bağlanan standart bir mikrofon (alıcı anteni) aracılığı ile alır, MATLAB üzerinde koşan fiziksel katman modülü ile işler ve sonucu ekrana yazdırır. 


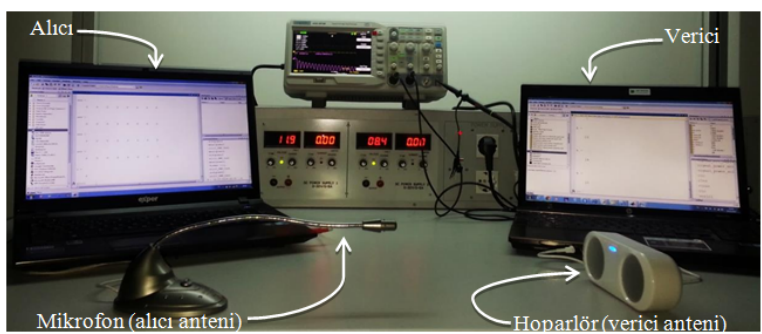

Şekil 3. Alıc1-verici gerçeklemesinin gerçek-zamanlı olarak çalışan halinin bir görüntüsü (A snapshot of the setup for transceiver design working in real-time)

Gerçek-zamanlı uygulamasından elde edilen sonuçlar Şekil 4'te iki adet kuramsal başarım eğrisi ile birlikte verilmiştir. Bu noktada Şekil 4'te verilen sonuçların, Şekil 3'te gösterilen kurulumdaki senaryodan elde edildiğinin belirtilmesi şu nedenlerden ötürü oldukça önemlidir: (i) Kablosuz haberleşme kanalı, ister akustik ister radyo tabanlı haberleşme olsun, değişik türlerde ve istatistiksel ölçeklerde sönümlenmelere yol açmaktadır. Dolayısıyla yankısız/yansımasız odalar ve uzay boşluğu gibi özel ortamlar hariç, hemen hemen hiçbir kablosuz haberleşme ortamında (1)'deki $d[\cdot]$, alıcı tarafa verici taraftan ayrıldığ andaki gibi ulaşmaz. (ii) Kablosuz haberleşme ortamı çoklu erişime açık olduğundan, genelde toplamsal gürültünün yanında girişimin bozucu etkisini de içerisinde barındırır. (iii) Son olarak, matematiksel modellemede benimsenen doğrusal yaklaşım, kullanılan donanımların (anten yapısı, güçlendiricilerin çalışma aralığı vb.) niteliğine ve/veya yeteneğine bağlı olarak doğrusal olmayan davranışlar sergileyebilir.

$\mathrm{Bu}$ çalışmada ortaya konan gerçeklemedeki alıcı tasarımı, yukarıda sözü edilen durum ve senaryolardan ötürü ortaya çıkan sorunları bertaraf edecek bir dizi işaret işleme tekniğini içermektedir. Sözü edilen işaret işleme tekniklerinin başarımını arttırmak için de alıcı ve verici çifti birbirlerinin görüş açısı içerisinde, antenlerinin (hoparlör ve mikrofon) yönleri birbirlerine bakacak şekilde ve kısa mesafede konumlandırılmıştır.

$\mathrm{Bu}$ açıklamalar 1şığında ortaya konan gerçeklemenin sonuçları irdelenebilir. Şekil 4'te gerçeklemenin başarımı bilimsel dizinde sıkça kullanılan Rayleigh ve Rice OYF'lerine sahip sönümlenmeli kanalların kuramsal başarım eğrileri ile birlikte verilmiştir. Şekilde yatay eksenle verilen güç oranı değerleri ise şu şekilde elde edilmiştir: Öncelikle alıcının mikrofonu aracılığı ile sessiz bir ortamda güç ölçümü yapılmıştır. Daha sonra, gerçek-zamanlı haberleşme ölçümlerinde vericinin hoparlörü işletim sistemi arayüzü ile $\% 100, \% 75$ ve $\% 50$ ölçekte güç aktaracak biçimde ayarlanmıştır. Son olarak da yatay eksende görüntülenen İGO değerleri işaretin gücünün sessiz ortamda elde edilen gürültüye ait güce oranlanması sonucunda elde edilmiştir.
$\mathrm{Bu}$ koşullarda elde edilen sonuçlardan da görüldüğü üzere ortaya konan gerçekleme her iki kuramsal başarımdan da daha iyi sonuçlar vermektedir. Bunun nedeni, alıcı-verici çiftinin antenlerinin birbirlerine bakacak biçimde ve göreceli olarak yakın biçimde konumlandırılmasıdır.

Başarımın $K=3 \mathrm{~dB}$ ile verilen Rice tabanlı senaryoya göre daha iyi sonuç vermesinin nedeni ise alıcı tarafta uygulanan ek işaret işleme yöntemleridir.

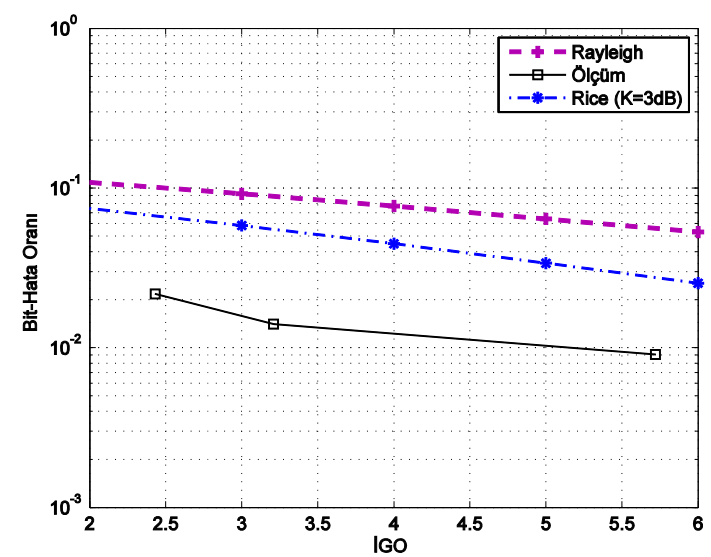

Şekil 4. Gerçek-zamanlı olarak çalıştırılan yazılımtabanlı kablosuz akustik alıcının başarımı (Real-time performance of the software-defined wireless acoustic receiver)

Son olarak, gerçeklemenin başarımının gerçek hayata daha uygun ancak daha karmaşık senaryolarda sınanması gerekmektedir. Hareketlilik, bütün kablosuz haberleşme sistemleri için hayati önem taşıdığından gerçeklemenin hareketli senaryolarda sınanması sağlanmıştır. Bağıl hareketi ortaya koyabilmek için verici sabit tutulup, değişik güzergâhlarda alıcının yürüme hızında yer değiştirmesi sağlanmıştır. İstenen İGO değerleri alıcıverici arası mesafenin ayarlanması ve verici gücünün (hoparlörün ses şiddetinin) arttırılıp, azalması ile sağlanmıştır. Elde edilen sonuçlar, bu alanda bilimsel dizinde karşılaştırma amaçlı olarak kullanılan simülasyon modelleri ile üretilen verilerle bir arada değerlendirilip, Şekil 5'te verilmiştir. Şekil 5'ten de görülebileceği üzere alıcının başarımı, azami Doppler kayması ile üstten sınırlandırılmış kuramsal başarımdan her zaman daha iyi sonuç vermektedir. Bu davranış, deney esnasında seçilen hareket yönünün rastgele belirlenmesi ve çok az olasıllkla azami Doppler kaymasına yol açacak güzergâhta hareket edilmesinden kaynaklanmaktadır. Ayrıca hareketliliğin, alıcı tarafta uygulanmayan ek işaret işleme yöntemleri nedeniyle Şekil 4'teki başarımdan daha düşük olmasına dikkat edilmelidir. Sayfa sınırlaması nedeniyle, benzer sonuçların elde edildiği diğer (örneğin, hem alıcının hem de vericinin ikisinin birden hareketli olduğu) senaryolara ilişkin görseller verilmemiştir. 


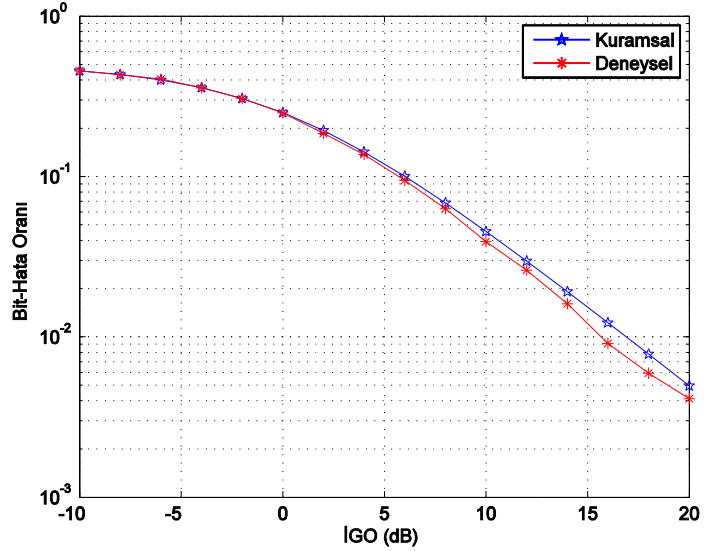

Şekil 5. Vericinin sabit, alıcının hareketli olduğu senaryolara ilişkin ölçüm sonuçları ve kuramsal verilerle karşılaştırılması (Comparison of the theoretical data with the measurement results where transmitter is fixed and receiver is mobile)

\section{SONUÇLAR VE ILERIYE YÖNELIK TARTIŞMALAR (CONCLUSIONS AND FUTURE DIRECTIONS)}

$\mathrm{Bu}$ çalışmada; akıllı radyo hedefi doğrultusunda, temel bantta çalışan bir alıcı-verici tasarımı ortaya konmuştur. Tasarımın bütün değişkenleri geliştirici tarafindan ayarlanıp, denetlenip, güncellenebilmektedir. Ek olarak k1sa mesafeli, kablosuz, akustik ve gerçek zamanlı çalışan bir yazılım-tabanlı öntür gerçeklemesi de yapılmıştır. Bu öntür; çeşitli yöntemlerin başarımlarının gerçekzamanlı olarak irdelenebileceği bir sınama ortamıdır.

Akıllı radyo değişen ortam ve haberleşme koşullarına uyumluluk gösteren bir teknolojidir. Uyumluluk her duruma göre en uygun haberleşme stratejisini belirlemeyi gerektirdiğinden akıllı radyo; bant genişliği, pil ömrü, gönderilen işaretin gücü ve bellek boyutu gibi kısıtlı kaynaklarını en verimli biçimde kullanmak zorundadır. Bir bakımdan yeşil haberleşmenin temellerini de oluşturan bu davranış biçimi, akıllı radyo öntür gerçeklemelerinde kullanılan YTP'lerin ve ilgili donanımların sözü edilen stratejileri destekleyecek hızda, makul maliyetler ile düşük güç tüketimi ölçütleri uyarınca üst düzey esneklikte, verimlilikte ve biçimde geliştirilmesini gerektirmektedir. Özellikle haberleşme katmanları arası veri dolaşımını gerektiren tasarımlar, kablosuz girişim, değişken haberleşme ortamına ayak uydurma gibi sorunlar geleneksel optimizasyon yöntemleri ile hızlı ve verimli bir biçimde çözülememektedir. Dolayısıyla YTP'lerin sezgisel yöntemleri ve yapay zekâ yaklaşımlarını da içerecek biçimde geliştirilmesi kaçınılmazdır. Gerçek akıllı radyo, hizmet sağlayıcı tarafından öne sürülen yeni bir protokole, tekniğe ya da bir güncellemeye ilişkin yazılım modülünü kablosuz olarak alıp (indirip), yazılım-tabanlı platformlar sayesinde derhal kullanılır duruma geçirebilmelidir. Açıktır ki bu yapı, hem YTP'nin kendisine hem de ilgili modülün güvenliğine ilişkin kaygıları gündeme getirmektedir. Dolayısıyla YTP'ler ve ilgili modüller çok yüksek seviyeli güvenlik mekanizmaları çerçevesinde geliştirilmelidir. Görüldüğü üzere akıllı radyonun gerçekte olması hedeflenen yere ulaşması için birçok sorun bulunmaktadır. $\mathrm{Bu}$ sorunlar, ak1llı radyo kavramının en önemli ögesi olan YTP'lerin yukarıda önerilen yapıda tasarlanmaları sayesinde çözüme kavuşacaktır.

SEMBOLLER VE KISALTMALAR (SYMBOLS AND ABBREVIATIONS)

\begin{tabular}{|c|c|}
\hline$x[k]$ & $\begin{array}{l}k \text { dizinli ayrık zamanlı } x \\
\text { işareti }\end{array}$ \\
\hline$r[\cdot]$ & $\begin{array}{l}\text { Alınan işaretin temel banttaki } \\
\text { karşılığ } 1\end{array}$ \\
\hline$d[\cdot]$ & Gönderilen simge \\
\hline$n[\cdot]$ & Toplamsal gürültü \\
\hline$[a, b]$ & $\begin{array}{l}\text { Asgari } a \text {, azami } b \text { değeri ile } \\
\text { sinırlı kapalı aralık }\end{array}$ \\
\hline$\sim U D(a, b), \sim N(a, b)$ & $\begin{array}{l}\text { Verilen }[a, b] \text { değişkenleri ile } \\
\text { tanımlanan tekdüze ve normal } \\
\text { OYF'leri }\end{array}$ \\
\hline$x \doteq\left\{x_{0}, x_{1}, \ldots, x_{M-1}\right\}$ & $\begin{array}{l}\text { Ögeleri } x_{0}, x_{1}, \ldots, x_{M-1} \text { olan sonlu } \\
\text { küme }\end{array}$ \\
\hline$\forall k$ & Her $k$ için \\
\hline $\mathbf{R}$ & Gerçel sayılar kümesi \\
\hline$A_{m}$ & $\begin{array}{l}\text { Vericinin göndermek için } \\
\text { seçtiği } m \text { dizinli simge }\end{array}$ \\
\hline$p_{m}$ & $\begin{array}{l}\text { Vericinin göndermek için } A_{m} \\
\text { simgesini seçme olasılığ }\end{array}$ \\
\hline$b_{v}[\cdot], b_{a}[\cdot]$ & $\begin{array}{l}\text { Vericideki, alıcıdaki ikili sayı } \\
\text { (bit) }\end{array}$ \\
\hline$(\cdot)_{2}$ & İkili sayı (bit) \\
\hline$X \mapsto Y$ & $\begin{array}{l}\text { Bir } X \text { kümesinden bir } Y \\
\text { kümesine tanımlanan eşleme }\end{array}$ \\
\hline$f_{r}(\cdot)$ & Alınan işaret $r[\cdot]$ 'nin OYF'si \\
\hline$c[\cdot]$ & Alıcının kestirimi \\
\hline th & $\begin{array}{l}\text { Alıcının kestirimi için } \\
\text { kullandığ eşik değeri }\end{array}$ \\
\hline$\hat{A}_{m}$ & $\begin{array}{l}\text { Gönderilen simgenin } A_{m} \\
\text { olduğuna ilişkin alıcı } \\
\text { kestirimi }\end{array}$ \\
\hline$X \times Y$ & $\begin{array}{l}\text { Bir } X \text { kümesi ile bir } Y \\
\text { kümesinin Kartezyen çarpımı }\end{array}$ \\
\hline$c_{D}[\cdot], c_{H}[\cdot]$ & $\begin{array}{l}\text { Kestirimin doğru (hatası), } \\
\text { hatalı olduğu durumlar grubu }\end{array}$ \\
\hline$\left(A_{s}, \hat{A}_{1-s}\right)$ & Kestirimin hatalı olması olayı \\
\hline $\operatorname{Pr}\left(E_{1}\right)$ & $\begin{array}{l}\text { Herhangi bir } E_{1} \text { olayının } \\
\text { olma olasılığının ölçüsü }\end{array}$ \\
\hline$E_{1} \wedge E_{2}$ & $\begin{array}{l}\text { Herhangi bir } E_{1} \text { ve bir } E_{2} \\
\text { olayının bir arada olması olayı }\end{array}$ \\
\hline$X \cap Y$ & $\begin{array}{l}\text { Bir } X \text { kümesi ile bir } Y \\
\text { kümesinin kesişimi }\end{array}$ \\
\hline$\varnothing$ & Boş küme \\
\hline$\{x \mid f(x)\}$ & $\begin{array}{l}\text { Bir } f(x) \text { koşuluna uyan } x \\
\text { ögelerinden oluşan küme }\end{array}$ \\
\hline
\end{tabular}




\section{TEŞEKKÜR (ACKNOWLEDGMENT)}

Yazarlar, bu makalenin değerlendirme aşamasından kabul edilmesine kadar geçen süreçte verdikleri desteklerden ötürü öncelikle Editör ve Hakemlere, INF Teknoloji Ar-Ge'den Ali Boyacı'ya ve TLab.'den Fatma Nur Akı'ya da düzeltmelerdeki yardımları için teşekkürlerini iletmektedirler. Bu çalışma, İstanbul Ticaret Üniversitesi'nin [16] ile belirtilen projesi kapsamında desteklenmiştir.

\section{KAYNAKLAR (REFERENCES)}

1. Shared Spectrum Company Spectrum Occupancy Measurements Location 4 of 6: Republican National Convention, New York, Aug. 30, 2004Sept. 3, 2004.

2. Kulaç, S., Sazlı, M. H., "Enerji Verimli İşbirlikçi DTV Spektrum Algilama", Journal of The Faculty of Engineering and Architecture of Gazi University, Cilt 28, No 1, 77-84, 2013.

3. Mitola, J., Cognitive Radio An Integrated Agent Architecture for Software Defined Radio. Doktora Tezi, KTH Royal Inst. of Tech., Stockholm, İsveç.

4. Yarkan, S., Arslan, H., "Exploiting location awareness toward improved wireless system design in cognitive radio", IEEE Communications Magazine, Cilt 46, No 1, 128136, 2008.

5. Lien, SY., Chen, KC., Lin, Y., Liang, YC., "Cognitive Radio Resource Management For Future Cellular Networks", IEEE Wireless Communcaitons, Cilt 21, No 1, 70-79, 2014.

6. Yousefi'zadeh, H., Li, X., "Load Adaptive MAC: A Hybrid MAC Protocol for MIMO SDR MANETs", IEEE Transactions on Wireless Communications, Cilt 10, No 11, 3924-3933, 2011.

7. Donno, D. D., Ricciato, F., Tarricone, L., "Listening to Tags: Uplink RFID Measurements With an Open-Source Software-Defined Radio
Tool", IEEE Transactions on Instrumentation and Measurement, Cilt 62, No 1, 109-118, 2013.

8. Tan, K., Kim, K., Xin, Y., Rangarajan, S., Mohapatra, P., "RECOG: A Sensing-Based Cognitive Radio System with Real-Time Application Support", IEEE Journal on Selected Areas in Communications, Cilt 31, No 11, 2504-2516, 2013.

9. Lotze, J., Fahmy, S. A., Noguera, J., Doyle, L. E., "A Model-Based Approach to Cognitive Radio Design", IEEE Journal on Selected Areas in Communications, Cilt 29, No 2, 455-468, 2011.

10. Alluri, V. B., Heath, J. R., Lhamon, M., "A New Multichannel, Coherent Amplitude Modulated, Time-Division Multiplexed, Software-Defined Radio Receiver Architecture, and FieldProgrammable-Gate-Array Technology Implementation", IEEE Transactions on Signal Processing, Cilt 58, No 10, 5369-5384, 2010.

11. Kim, J., Hyeon, S., Choi, S., "Implementation of an SDR system using graphics processing unit", IEEE Communications Magazine, Cilt 48, No 3, 152-162, 2010.

12. Kucuk, K., Karakoc, M., Kavak, A., Yigit, H., "Üçüncü Nesil CDMA Sistemler İçin Yeni Bir Akıllı Anten Algoritması Gerçekleştirilmesi Ve Performans Analizi", Journal of The Faculty of Engineering and Architecture of Gazi University, Cilt 21, No 4, 801-808, 2006.

13. Lee, E. A., Messerschmitt, D. G., Digital Communication. Allied Pub. Ltd., ABD, 1994.

14. Sklar, B., Digital Communications: Fundamentals and Applications (2nd edn.), Prentice Hall, Upper Saddle River, ABD, 2001.

15. Proakis, J. G., Digital Communications, McGrawHill Int. Edn., NY, ABD, 2001.

16. İstanbul Ticaret Üniversitesi, Yayın Araştırma Proje Koordinasyon Kurulu Projesi, Çevrimiçi etkileşimli taşıt verisi toplama, işleme ve değerlendirme mobil uygulaması: Halo, İstanbul Ticaret Üniversitesi, İstanbul, 2014. 